\title{
Endogenous Variety and the Gains from Trade
}

\author{
Costas Arkolakis, Yale University \\ Svetlana Demidova, University of Georgia \\ Peter J. Klenow, Stanford University and NBER \\ Andrés Rodríguez-Clare, Penn State University and NBER
}

December 2007 


\section{Introduction}

There is a common perception that the gains from trade are larger than what quantitative general-equilibrium models of trade can explain. A recurring goal in the trade literature has been to find new channels through which such models could generate larger gains from trade. A prominent example is Romer (1994), where trade allows for the consumption of a higher variety of goods, and this generates additional benefits not included in standard calculations. Romer's argument is that, in the presence of fixed marketing or distribution costs, a sufficiently high tariff may imply not just lower imports, but no imports at all of a good. The result would be less variety in available consumer goods and less availability of specialized equipment and intermediate goods.

We start in section 2 by showing that the connection postulated by Romer between trade liberalization and increasing variety is present in the data by focusing on the experience of Costa Rica from 1986 to 1992. During this period, the average tariff on consumer (intermediate) goods fell from $48.8 \%$ to $22.5 \%$ ( $11.2 \%$ to $10 \%$ ) and the variety of consumer (intermediate) goods imported increased by $25.6 \%$ (14.7\%). Romer performed a numerical exercise to show that the welfare losses arising from reduced variety may be an order of magnitude larger than those associated with the standard trade analysis (the Harberger Triangles). In section 3 we use our Costa Rican data to evaluate this result by applying a method introduced by Feenstra (1994) to compute the gains from increased imported variety. For consumer goods we find gains of around $0.3 \%$ in spite of the much larger increase in variety, while for intermediate goods we find no gains at all. The relatively low welfare gains arise because of strong heterogeneity across imported goods, which implies that, upon trade liberalization, the new varieties are imported in small quantities and hence contribute little to welfare. We refer to this effect, not taken into account by Romer (1994) nor some of his followers (Rutherford and Tarr, 2002), as the effect of "curvature" in weakening the variety gains from trade. In section 4 we relate this result to recent models of firm-level heterogeneity and derive a simple formula that shows the effect of curvature.

The reader may find it surprising that we find small variety gains from trade liberalization in Costa Rica given that Broda and Weinstein (2006) find large gains from imported variety for the U.S. But the two exercises are very different. Broda and Weinstein (2006) quantify the gains from the introduction of new varieties in the rest of the world that are eventually 
imported into the United States. This is very different from the effects of trade liberalization because, whereas an expansion of imported variety responding to trade liberalization entails consuming less desirable varieties (that's why they weren't imported before), an expansion of imported variety in time is more likely to be associated with the introduction of important (infra-marginal) varieties abroad which are more likely to contribute significantly to welfare.

These results do no take into account the effect of trade liberalization on domestic variety. But it seems reasonable to think that an increase in import competition would cause a decline in domestic variety as domestic firms exit. In fact, the evidence reveals that trade liberalization leads to exit by domestic firms (Tybout, 2003). Consistent with this, domestic variety is endogenous in most recent models and falls with a decline in trade costs. ${ }^{1}$ In section 5 we present a model with firm-level increasing returns, differentiated goods, monopolistic competition, endogenous variety and free entry to show that, as in Baldwin and Forslid (2004), total variety (domestic plus imported) can either increase, decrease or remain constant with trade liberalization. More importantly and surprisingly, the gains from trade do not depend on what happens to total variety.

More generally, we find that the real wage is ultimately dependent on the ratio of imports to total expenditure with an elasticity that is the same across a range of models. This result is also relevant in relation to the notion that trade leads to a reallocation of economic activity towards firms with higher productivity (Melitz, 2003, Bernard et. al., 2003), and that this "provides a non-traditional source of welfare gains from trade" (Bernard et. al., 2007 - JEP paper). We argue that, conditional on the estimated elasticities of trade with respect to trade costs, the implications of models with increasing returns, endogenous variety, free or restricted entry, and heterogeneity across firms have exactly the same implications for welfare gains from trade liberalization as traditional models. ${ }^{2}$ In our view, the contribution of the new trade models is not to provide new channels for gains from trade, but rather to explain the levels and microfoundations of trade that we observe.

\footnotetext{
${ }^{1}$ See Melitz (2003), Chaney (2007), Eaton, Kortum and Kramarz (2007), and Arkolakis (2006).

${ }^{2}$ This assertion is valid under the standard assumption that productivities are distributed Pareto, but may not be valid under alternative distributions.
} 


\section{Variety and Tariffs in Costa Rica}

Our dataset consists of Costa Rican imports of each of 1,338 products from up to 111 countries over 1986 to 1992. The product categories correspond to the NAUCA II classification used by Central American countries over this period. This classification does not conform to the more widely used SITC. In terms of the number of categories the NAUCA II level of detail corresponds to 5 digit categories in the SITC. We have data on kilos and US dollars of imports (c.i.f.) for each product-country-year. Our source for this data is the Central Bank of Costa Rica, which in this period applied a tariff (called sobretasas) to these imports, with the rate varying over time and across products. From the Costa Rican Finance Ministry we obtained data on Costa Rica's second tariff (called tarifa), which likewise varies across time and products. Our sample is bracketed by 1986 and 1992 since Costa Rica used different product classification systems before and after these years.

We take country of origin as the demarcation of a variety (i.e., cars from the US are a different variety than cars from Germany or Japan) and think of total variety for a good as the number of countries from which there were imports in a product category. ${ }^{3}$ (The model we present in Section 5 interprets variety in the more traditional sense of monopolistic competition and product differentiation, where variety corresponds to the number of firms that sell in a market.)

Table 1 provides some summary statistics for the dataset. Variety rose from an average of 8.2 in a category in 1986 to 11.5 in 1992 for the 369 consumer goods, and from 7.9 to 8.8 for the 969 intermediate and capital goods (hereafter just intermediate goods). Weighting each product category by total dollar imports, variety rose from 19.1 to 24 for consumer goods, and from 13.6 to 15.6 for intermediate goods. Over this period average tariffs fell from $48.8 \%$ to $22.5 \%$ for consumer goods, and from $17.1 \%$ to $12.9 \%$ for intermediate goods. ${ }^{4}$ Dollar-weighted tariffs fell from $43.3 \%$ to $20.3 \%$ for consumer goods, and from $11.2 \%$ to $10.0 \%$ for intermediate goods. Consumption goods imports rose from 5.4\% of GDP in 1986 to $8.1 \%$ in 1992. The share of intermediate goods imports rose from $23.3 \%$ to $27.2 \%$ of GDP over the same period.

Of course, these aggregate trends do not establish that tariff reduction, as opposed to some other factor (such as income and population growth), caused the increases observed in variety

\footnotetext{
${ }^{3}$ See Klenow and Rodríguez-Clare (1997) for a discussion of the limitations of this measure of variety.

${ }^{4}$ The standard deviation of tariff rates also fell sharply, from $37 \%$ to $12 \%$ for consumer goods, and from $17 \%$ to $7 \%$ for intermediate goods.
} 
and import shares. Evidence that variety increased in product-years with bigger tariff reductions would be more compelling. Before examining the micro evidence on tariffs and variety, however, it is useful to examine the underlying premise that greater market size boosts variety, as implied by fixed costs of importing a given product from a given country. Table 2 presents the results from regressing variety on market size for consumer and intermediate goods, respectively. Each observation is a product-year, e.g. cars in 1990. The dependent variable is the natural log of variety, while the independent variable is the natural log of market size (imports of a product summed across all countries in a year). Year effects are included to deal with general inflation in dollar imports. The results show that variety is greater in larger markets, both for consumer and intermediate goods. The relationship is statistically and economically significant: a $1 \%$ bigger market has $0.26 \%$ more variety on average (standard errors around $0.004 \%$ ). The $R^{2 \prime} s$ indicate that almost half the variation in variety across products is associated with market size. Instead of larger markets pulling in more varieties due to fixed costs, an alternative intepretation of this result is that some product categories are arbitrarily broader than others. Exogenously larger categories could include more countries just because they are more aggregated. To see if the results owe entirely to cross-sectional variation in product size, we regressed variety on size controlling for product dummies. These results are also reported in Table 2. The size of the elasticity is roughly halved to 0.12 , but it remains economically and statistically significant (standard errors around 0.006). ${ }^{5}$ The fact that the elasticity of variety with respect to market size is well below one, however, implies either that fixed costs are increasing in market size (albeit less than proportionately) or ever-less-important varieties are imported by bigger markets.

Measuring market size as country GDP, Hummels and Klenow (2002) similarly found a strong relationship between market size and import variety. For 6-digit categories they found that larger economies imported proportionately more, and a doubling of importer size was associated with importing from about $28 \%$ more countries. As within Costa Rica, bigger markets seemed to import "smaller" varieties, as the new varieties accounted for only $19 \%$ of the additional imports of larger economies. Similarly, Eaton, Kortum and Kramarz (2007), henceforth EKK, document that more French firms (including those that have small sales in

\footnotetext{
${ }^{5}$ Measuring market size as country GDP, Hummels and Klenow (2002) similarly found a strong relationship between market size and import variety. They looked at a set of 59 countries importing from 115 countries across 5,000 6-digit categories in 1995. Larger economies imported proportionately more, and a doubling of importer size was associated with importing from about $28 \%$ more countries within 6 -digit categories. As within Costa Rica, bigger markets seemed to import "smaller" varieties, as the new varieties accounted for only $19 \%$ of the additional imports of larger economies.
} 
France) export to larger economies, consistent with models with fixed costs of entry and with the idea that larger economies pull in less valuable varieties on the margin.

With some confidence that market size affects variety, we examined whether products with falling tariffs see rising variety. Our identifying assumption is that product differences in tariff changes are exogenous. Table 3 presents the results from regressing the natural log of variety on the natural log of the gross tariff rate. Including year and product dummies, we find an economically and statistically significant negative association between variety and tariffs, with a $1 \%$ higher tariff rate going along with $0.82 \%$ less consumer import variety and $0.29 \%$ less intermediate import variety (standard errors around 0.10\%). Consistent with the hypothesis that higher tariffs reduce variety by shrinking the market, Table 3 also reports that a $1 \%$ higher tariff lower total imports by $1.83 \%$ in consumer product categories and $0.54 \%$ in intermediate categories (standard errors of $0.29 \%)^{6}$

The association between available varieties and trade has been studied for other trade liberalization episodes. Kehoe and Ruhl (2003) find that varieties that accounted for only 10 percent of trade before liberalization may account for as much as 40 percent of trade following liberalization. While this finding indicates substantial adjustments in the extensive margin, further investigation reveals that new varieties are typically associated with small sales. Arkolakis (2006) finds that while the total number of 6-digit (Harmonized-System) varieties that were imported by the U.S. from Mexico increases substantially with NAFTA (at least 30\% depending on different definitions) the contribution of these goods to new trade is roughly $5 \%$. This is also consistent with the findings of Eaton, Eslava, Kugler and Tybout (2007) for Colombian firms. They find that firms that were not exporting the previous year into an destination market have typically very small sales there.

\section{Variety Gains in Costa Rica}

Feenstra (1994) shows how to adjust the standard import price index for changing variety, including our case where marginal varieties appear less important than inframarginal ones. We refer to this adjustment as the Feenstra Ratio and denote it by $F$, with

$$
F=\left(\frac{\sum_{\Omega^{\prime}} v_{i}^{\prime} / \sum_{\Omega^{\prime} \cap \Omega} v_{i}^{\prime}}{\sum_{\Omega} v_{i} / \sum_{\Omega^{\prime} \cap \Omega} v_{i}}\right)^{-1 /(\sigma-1)}
$$

\footnotetext{
${ }^{6}$ Related, Arkolakis (2006) showed that U.S. tariff declines associated with NAFTA led to an increase in imported variety from Mexico, but that the new goods were imported in relatively small quantities.
} 
Here $v_{i}$ are imports from country-product pair $i$ in 1986 and $\Omega$ is the set of country-product pairs imported in 1986, and the corresponding values with primes refer to 1992. Table 4 has the ingredients of the Feenstra Ratio as well as the ratio itself. The first row says that current dollar imports grew by a factor of 2.87 for consumer goods and 1.90 for intermediate goods from 1986 to 1992. But the next row indicates that imports grew almost as much for "common" countryproduct pairs (those with imports in both 1986 and 1992): by a factor of 2.83 for consumer goods and 1.90 for intermediate goods. The following row says that consumer imports grew $1.4 \%$ faster than for common country-product pairs, whereas all intermediate imports grew at the same rate as for common pairs. For the Feenstra Ratios we use $\sigma=6$ based on estimates in Broda and Weinstein (2006) for levels of aggregation that bracket the level of aggregation in the Costa Rican product categories. Using this value the Feenstra Ratio is 0.997 for consumer goods and 1 for intermediates, suggesting a very modest downward adjustment of $0.3 \%$ to the price index for consumer imports, and none at all for intermediates.

How can we reconcile such modest adjustments with the surge in variety of about $25 \%$ for consumer goods (from 19.1 to 24 in Table 1) and $15 \%$ for intermediate goods (from 13.6 to 15.6)? The answer is that the new varieties must not be as important as incumbent ones. For example, adding South Korea as a source of cars may not be as important as already having access to cars from Japan, the U.S., and Germany.

\section{The role of curvature}

Consider a continuum of foreign varieties indexed by $s$ and ordered in terms of decreasing quality or increasing marginal cost. With CES preferences and an elasticity of substitution $\sigma>1$, there will be some $n$ such that all varieties $s \in[0, n]$ are imported. This $n$ will be lower than total foreign variety if importing entails a fixed cost. Consider an increase in imported variety from $n$ to $n^{\prime}$. The Feenstra Ratio in this case would be

$$
F=\left(\frac{\int_{0}^{n^{\prime}} v(s) d s}{\int_{0}^{n} v(s) d s}\right)^{-1 /(\sigma-1)}
$$

Taking the $\log$ derivative of this with respect to $n^{\prime}$ we see that

$$
\frac{\partial \ln F}{\partial \ln n^{\prime}}=-\frac{1}{\sigma-1}\left(\frac{v\left(n^{\prime}\right)}{\left(1 / n^{\prime}\right) \int_{0}^{n^{\prime}} v(s) d s}\right)
$$


The first term is the standard elasticity of welfare with respect to variety (love of variety) under CES preferences. The second is an adjustment for "curvature." A low value for this term implies that marginal varieties have either low quality or preference parameters, or a high international price, so the gains from increased variety are smaller.

A nice expression for this curvature adjustment can be obtained if we assume that the preference parameter, quality, or productivity is distributed Pareto. Under the productivity interpretation and with monopolistic competition, domestic prices of foreign varieties will be proportional to the inverse of productivity, $\phi$, and $v(s)$ will be proportional to $\phi(s)^{\sigma-1}, v(s)=$ $A \phi(s)^{\sigma-1}$ for some $A>0$. Assume that there is a continuum of goods with exogenous measure $M$ whose international price is drawn from a Pareto distribution, so that $\operatorname{Pr}(\phi<\widetilde{\phi})=G(\widetilde{\phi}) \equiv$ $1-(b / \widetilde{\phi})^{\theta}$ for $\widetilde{\phi} \geq b>0$. We assume that $\theta>\sigma-1$. Note for future reference that an increase in $\theta$ implies less dispersion, in that more and more of the productivities are closer to the minimum $b$. If the fixed importing cost is the same across varieties, then profits will be increasing in productivity $\phi$,and there will be a $\phi^{*}$ such that all inputs with $\phi>\phi^{*}$ are imported. Imported variety is then $n=M * \operatorname{Pr}\left(\phi>\phi^{*}\right)$ and hence

$$
\int_{0}^{n} v(s) d s=\int_{\phi^{*}}^{\infty} v(\phi) \frac{d G(\phi)}{1-G\left(\phi^{*}\right)}=\frac{A n \theta\left(\varphi^{*}\right)^{\sigma-1}}{\theta-(\sigma-1)}
$$

Plugging into (1) we get:

$$
\varepsilon \equiv-\frac{\partial \ln F}{\partial \ln n}=\frac{1}{\sigma-1}-\frac{1}{\theta}
$$

Note that high curvature (low $\theta$ ) decreases the impact of love of variety. ${ }^{7}$

As mentioned in section 2, in Costa Rica the mean (weighted) variety for consumer goods went from 19.1 in 1986 to 24 in 1992, a increase of $25.6 \%$. Given the result in the previous section that the Feenstra Ratio for this period is 0.997 (a welfare gain of $0.3 \%$ thanks to increased variety for $\sigma=6$ ), we have that $0.256 * \varepsilon=0.003$. Using the expression in (2) for $\varepsilon$ and $\sigma=6$, this implies that $\theta=5.3$.

For comparison, EKK use data on exports and domestic sales by French firms to estimate that $\theta /(\sigma-1)=1.5$. If $\sigma=6$ this means $\theta=7.5$, just a bit lower than the central value for $\theta$ (i.e., $\theta=8$ ) in Eaton and Kortum (2002). The Costa Rican experience suggests somewhat higher curvature than this. This difference matters for the welfare implications of the observed

\footnotetext{
${ }^{7}$ This result does not depend on the implicit assumption that there is a unique fixed cost for all foreign varieties. In separate work we have established that if the fixed cost is distributed Pareto and is independent of $\phi$ then this result remain valid.
} 
increase in variety in Costa Rica. If instead of $\theta=5.3$ we used the lower curvature associated with $\theta=7.5$, then $\varepsilon=0.067$, and the variety gains would be $1.7 \%$ rather than our $0.3 \%$. Of course, this difference could be due to the fact that in the Costa Rican data we are interpreting variety with country of origin, whereas in EKK variety is associated with the number of firms that serve a particular market.

\section{$5 \quad$ Endogenous Domestic Variety and Free Entry}

The previous discussion has taken foreign variety to be exogenous and simply performed a comparative statics exercise with respecto to variety. We also ignored any effects of trade liberalization on the variety of goods offered by domestic firms. What happens to total available variety (domestic plus foreign) following trade liberalization? ${ }^{8}$ Baldwin and Forslid (2004) address this question through a modified Melitz (2003) model with two asymmetric countries under exogenous wages. They show that if the fixed cost of supplying the home market is higher for foreign than for domestic firms, then total available variety falls with a decline in the costs of trade. They refer to this as the "anti-variety effect" of trade liberalization. Here we present a model with endogenous wages and $N>2$ countries to generalize the Baldwin and Forslid (2004) and, more importantly, to show that conditional on the effect of trade liberalization in imports, all major quantitative models of trade deliver the same gains. ${ }^{9}$

As above, there is a continuum of goods and preferences are CES with an elasticity of substitution $\sigma>1$. We denote the exporting country by $i$ and the importing country by $j$, where $i, j=1, \ldots, N$. Given a measure of $L_{j}$ representative consumers in country $j$, the demand for a firm with productivity $\phi$ from country $i$ charging a price $p_{i j}(\phi)$ in country $j$ is $x_{i j}(\phi)=p_{i j}(\phi)^{-\sigma} P_{j}^{\sigma-1} w_{j} L_{j}$, where $w_{j}$ is the wage and $P_{j}$ is the price index. ${ }^{10}$ Each firm must pay a fixed cost (in terms of labor in the destination country) to enter a particular market that varies across country pairs, $f_{i j}$, and also incurs iceberg transportation $\operatorname{costs} \tau_{i j}>1$ with

\footnotetext{
${ }^{8}$ Demidova and Rodríguez-Clare (2007) study the optimal trade policy in a setting where domestic and foreign variety are endogenous for the case of a small country.

${ }^{9}$ One drawback of the model we present here is that we treat tariffs as transportation costs, meaning that we don't deal with the way in which the associated revenues feed back into the demand for goods. For the points we make here, however, this is not problematic. For welfare analysis modelling tariffs explicitly is essential (see Demidova and Rodríguez-Clare, 2007).

${ }^{10}$ The price index is $P_{j}$, where $P_{j}^{1-\sigma}=\sum_{v} \int_{0}^{\infty} p_{i j}(\phi)^{1-\sigma} M_{i j} \mu_{i j}(\phi) d \phi, \mu_{i j}(\phi)$ is the distribution of productivities of firms originating from country $i$ conditional on selling to country $j$ and $M_{i j}$ is the measure of firms from country $i$ selling to country $j$.
} 
$\tau_{i i}=1$. Firms from $i$ with $\phi \geq \phi_{i j}^{*}$ will export to market $j$. The cut-off productivities $\phi_{i j}^{*}$ are determined by equating maximum profits to zero. This yields

$$
\left(\phi_{i j}^{*}\right)^{\sigma-1}=\frac{f_{i j}}{\left(\frac{\sigma}{\sigma-1} \tau_{i j} w_{i}\right)^{1-\sigma} \frac{1}{\sigma} \frac{L_{j}}{P_{j}^{1-\sigma}}} .
$$

Firms have to pay a fixed entry cost, $f_{e}$, in order to enter the market and draw a productivity realization. New entrants draw their productivity from a Pareto distribution, as above. ${ }^{11}$ If a firm gets a productivity draw below $\phi_{i i}^{*}$, it exits immediately without operating. Thus, because of free entry, in equilibrium, expected profits of a firm must equal to entry costs. ${ }^{12}$ In other words, the product of the probability of getting a productivity draw above $\phi_{i i}^{*}$ and the average profits must equal the entry cost. The free entry condition together with the labor market clearing condition implies that the equilibrium number of firms producing in country $i$ is

$$
N_{i}=\frac{(\sigma-1) b_{i}^{\theta} /\left(\phi_{i i}^{*}\right)^{\theta}}{\theta \sigma f_{e}} L_{i} .
$$

Notice that total export sales from country $i$ to $j$ are:

$$
T_{i j}=\underbrace{\left(\frac{\phi_{i i}^{*}}{\phi_{i j}^{*}}\right)^{\theta} N_{i}}_{\text {firms }} \underbrace{w_{j} f_{i j} \frac{\sigma \theta}{\theta-\sigma+1}}_{\text {average sales of operating firms }}
$$

Define the fraction of total income of country $j$ spent on goods from country $i$ by $\lambda_{i j}$. Using the definition of total sales from $i$ to $j$ and equation (4) we have:

$$
\lambda_{i j}=\frac{L_{i} b_{i}^{\theta}\left(\tau_{i j} w_{i}\right)^{-\theta} f_{i j}^{1-\theta /(\sigma-1)}}{\sum_{v} L_{v} b_{v}^{\theta}\left(\tau_{v j} w_{v}\right)^{-\theta} f_{v j}^{1-\theta /(\sigma-1)}} .
$$

It is quite remarkable that, even with free entry, the equation determining market shares, (6), turns out to be quite similar to the one introduced by Eaton and Kortum (2002). In particular, market share appears to be changing in the same elasticity with respect to the cost

\footnotetext{
${ }^{11}$ We assume that the parameters of the model are such that the lower productivity threshold $\phi_{i j}^{*}>\phi_{i i}^{*}>b_{i}$, $\forall i \neq j$.

${ }^{12}$ Essentially, we assume that there exists a perfect capital market which requires firms to pay a fixed entry cost before drawing a productivity realization. Consequently, we multiply the LHS by $1-G\left(\phi_{i i}^{*}, b_{i}\right)$, the probability of obtaining the average profit, since firms with profits below this average necessarily exit the market. Alternatively, we could have to specified a more general case of an infinite horizon model with an exogenous probability of death for each firm, $\delta$, as in Melitz (2003). In this case the expected profits from entry should equal the discounted entry cost, in equilibrium.
} 
factors, $\tau_{i j}$ and $w_{i}$. In fact, it is worth noticing that this expression is identical to that of Chaney (2007), who does not assume free entry, but a predetermined number of potential suppliers. ${ }^{13}$

Using equation (5) and the definition of $\lambda_{i j}$ that implies $T_{i j}=\lambda_{i j} w_{j} L_{j}$, it follows that the measure of firms from country $i$ selling to $j, M_{i j}$, can be written as:

$$
M_{i j}=\lambda_{i j} \frac{L_{j}}{f_{i j \frac{\sigma \theta}{\theta-\sigma+1}}} .
$$

Thus, total varieties offered in country $j$ are given by:

$$
\sum_{v} M_{v j}=\frac{L_{j}}{f_{j j} \frac{\sigma \theta}{\theta-\sigma+1}}+\frac{L_{j}}{\frac{\sigma \theta}{\theta-\sigma+1}} \sum_{v \neq i} \lambda_{v j}\left(\frac{1}{f_{v j}}-\frac{1}{f_{j j}}\right)
$$

This is a generalization of the Baldwin and Forslid (2004) result. In particular, increasing any $\lambda_{v j}$ (trade liberalization) has an anti-variety effect iff $f_{v j}>f_{j j}, \forall v \cdot{ }^{14}$ Intuitively, if $f_{v j}>f_{j j}$ then the marginal variety from country $v$ entails a lower price than the marginal domestic variety, so for each new foreign variety more than one domestic variety is displaced.

In this class of models, welfare for each representative consumer is given by $C_{j}=w_{j} / P_{j}$ ,which does not depend on the assumption of free entry. Using (3) and (6) we can express real wages as

$$
\frac{w_{j}}{P_{j}}=\lambda_{j j}^{-1 / \theta} L_{j}^{1 /(\sigma-1)}\left(\frac{b_{j}^{\theta} f_{j j}^{1-\theta /(\sigma-1)}}{f_{e}\left(\frac{\sigma}{\sigma-1}\right)^{\theta}(\sigma)^{\theta /(\sigma-1)}} \frac{\sigma-1}{\theta-\sigma+1}\right)^{1 / \theta} .
$$

Consider first a closed economy, with $\lambda_{j j}=1$. A larger population increases welfare with an elasticity of $1 /(\sigma-1)$. This is the standard result in models with love of variety and no heterogeneity, but differs from the results in Chaney (2007), EKK, and Arkolakis (2006), where this elasticity is $1 /(\sigma-1)-1 / \theta$. The reason why curvature does not affect the gains from size in our set-up is that the number of goods $\left(N_{j}\right)$ produced by an economy increases proportionately with $L_{j}$. Thus, contrary to models with no free entry, consumers in a country with larger population are not forced to consume varieties produced with lower productivities. On the other hand, a decline in the fixed cost of operation, $f_{j j}$, increases welfare with elasticity $1 /(\sigma-1)-1 / \theta$. Here we see how curvature decreases the variety gains associated with love

\footnotetext{
${ }^{13}$ Chaney (2007) essentially dispenses of the free entry condition this way. In his model some firms may still not operate since they have low productivity.

${ }^{14}$ Notice that the analysis in this section does not depend on the assumptions of free entry and symmetry across countries, but only on Dixit Stiglitz demand, CRS production technology and Pareto distribution of productivities.
} 
of variety. A decline in $f_{e}$, on the other hand, increases welfare with elasticity $1 / \theta$ - higher curvature entails a higher elasticity. The reason for this is that a lower $f_{e}$ leads to more entry while the number of operating firms remains the same. This entails more selection, the benefits of which are increasing with heterogeneity, or $1 / \theta$.

Trade costs, $\tau_{i j}$, and marketing costs, $f_{i j}$, affect real wages only indirectly through $\lambda_{j j}$. Thus, we can think of the welfare effects of trade liberalization as a reduction in $\lambda_{j j}$. In fact, in a proper calibration exercise, looking at the effects of trade liberalization involves matching $\lambda_{j j}$ before and after the trade liberalization. In this model, $\lambda_{j j}$ influences welfare with an elasticity of $-1 / \theta$, exactly the same way as in Eaton and Kortum's (2002) model of pure Ricardian trade (with no variety) and also the same as in Chaney (2007) and Arkolakis (2006). It is important to note that this happens even if $f_{i j} \neq f_{j j}$, so that changes in $\lambda_{j j}$ do affect total variety. To understand this, consider the case with $f_{i j}<f_{j j}$, so that an increase in $\lambda_{i j}$ (with a corresponding decline in $\lambda_{j j}$ ) increases total variety. Given $f_{i j}<f_{j j}$, the varieties that enter from abroad have prices that are higher than the domestic ones that are displaced, and it turns out that this exactly compensates the gains associated with increased variety.

This result implies that, conditional on the change in $\lambda_{j j}$ and given a value for $\theta$, a model with monopolistic competition, free entry and endogenous variety, delivers the same gains from trade liberalization as a same model with no free entry (Chaney 2007 or Arkolakis 2006) and a Ricardian trade model (Eaton and Kortum, 2002). ${ }^{15}$ The broader implication is that given the estimated elasticities of trade flows with respect to trade costs, the volume of trade itself determines the associated gains. Contrary to what many have claimed, new trade models don't really offer new gains from trade, but do allow us to better understand the levels and patterns of trade that we observe.

\footnotetext{
${ }^{15}$ It can also be shown that in Krugman's (1980) model of trade, where varieties are homogenous and there are no fixed costs of trade (so variety is the same in all countries), the gains from trade are proportional to $\lambda_{i i}^{-1 /(\sigma-1)}$. Again, conditional on the change in $\lambda_{i i}$, and noting that the relevant elasticity estimated in this model is $\sigma-1$ rather than $\theta$, then the gains from trade are the same.
} 


\section{Bibliography}

Arkolakis Costas, 2006, "Market Penetration Costs and the New Consumers Margin in International Trade," mimeo, Yale University.

Bernard et. al.

Broda, Christian and David E. Weinstein (2006), "Globalization and the Gains from Variety," Quarterly Journal of Economics 121 (May), 541-585.

Baldwin E. Richard, and Rikard Forslid, 2007, "Trade liberalisation with heterogeneous firms," mimeo

Chaney Thomas, 2007, "The Intensive and The Extensive Margin of International Trade," mimeo, University of Chicago

Eaton Jonathan, and Samuel Kortum, "Technology, Geography, and Trade," Econometrica, 2002, 70(5), pp. 1741-79.

Feenstra, Robert C. (1994), "New Product Varieties and the Measurement of International Prices," American Economic Review 84 (March), 157-177.

Hummels, David and Peter J. Klenow (2002), "The Variety and Quality of a Nation's Trade," NBER Working Paper 8712 (January).

Melitz, Marc, 2003, "The Impact of Trade on Intra-Industry Reallocations and Aggregate Productivity," Econometrica, 71 (6).

Tybout, James, 2003, "Plant- and Firm-level Evidence on the 'New' Trade Theories," in E. Kwan Choi and James Harrigan, ed., Handbook of International Trade, Oxford: Basil-Blackwell, 2003. 
Table 1

Mean Tariffs and Variety in 1986 and 1992 in Costa Rica

\begin{tabular}{|c|c|c|c|c|c|}
\hline & & \multicolumn{2}{|c|}{ Consumer } & \multicolumn{2}{|c|}{ Intermediate } \\
\hline & & 1986 & 1992 & 1986 & 1992 \\
\hline \multirow{2}{*}{ Unweighted } & Mean Tariff & 48.8 & 22.5 & 17.1 & 12.9 \\
\hline & Mean Variety & 8.2 & 11.5 & 7.9 & 8.8 \\
\hline \multirow{3}{*}{ Weighted } & Mean Tariff & 43.3 & 20.3 & 11.2 & 10.0 \\
\hline & Mean Variety & 19.1 & 24.0 & 13.6 & 15.6 \\
\hline & Import Share & 5.4 & 8.1 & 23.3 & 27.2 \\
\hline
\end{tabular}

Table 2

The Impact of Market Size on Variety

\begin{tabular}{|c|c|c|c|c|}
\hline \multirow[b]{2}{*}{ Market Size } & \multicolumn{2}{|c|}{ Consumer } & \multicolumn{2}{|c|}{ Intermediate } \\
\hline & $\begin{array}{c}0.264 \\
(0.005)\end{array}$ & $\begin{array}{c}0.121 \\
(0.008)\end{array}$ & $\begin{array}{c}0.257 \\
(0.003)\end{array}$ & $\begin{array}{c}0.121 \\
(0.004)\end{array}$ \\
\hline Year dummies & Yes & Yes & Yes & Yes \\
\hline Product dummies & No & Yes & No & Yes \\
\hline $\bar{R}^{2}$ & 0.479 & 0.883 & 0.465 & 0.882 \\
\hline \# observations & \multicolumn{2}{|c|}{2,583} & \multicolumn{2}{|c|}{6,783} \\
\hline
\end{tabular}


Table 3

The Impact of Tariffs on Variety and Market Size

\begin{tabular}{|c|c|c|c|c|}
\hline & \multicolumn{2}{|c|}{ Consumer } & \multicolumn{2}{|c|}{ Intermediate } \\
\hline & Variety & Market Size & Variety & Market Size \\
\hline Tariffs & $\begin{array}{c}-0.818 \\
(0.111)\end{array}$ & $\begin{array}{c}-1.832 \\
(0.291)\end{array}$ & $\begin{array}{c}-0.289 \\
(0.102)\end{array}$ & $\begin{array}{c}-0.540 \\
(0.291)\end{array}$ \\
\hline $\bar{R}^{2}$ & 0.873 & 0.873 & 0.867 & 0.847 \\
\hline \# observations & \multicolumn{2}{|c|}{2,583} & \multicolumn{2}{|c|}{6,783} \\
\hline
\end{tabular}

Table 4

Feenstra Ratios

\begin{tabular}{ccc}
\hline \hline [1992 Imports / 1986 Imports] & Consumer & Intermediate \\
All country-product pairs & 2.869 & 1.904 \\
Common country-product pairs & 2.829 & 1.904 \\
All / Common & 1.014 & 1.000 \\
Feenstra Ratio with $\sigma=6$ & 0.997 & 1.000 \\
\hline \hline
\end{tabular}

